\title{
Relationship between Valence States of Copper in Aluminophosphate Glasses and the Emission Properties
}

\author{
Hirokazu Masai, ${ }^{1 *}$ Hironori Ofuchi, ${ }^{2}$ Go Okada ${ }^{3}$ \\ Noriaki Kawaguchi, ${ }^{4}$ and Takayuki Yanagida ${ }^{4}$ \\ ${ }^{1}$ National Institute of Advanced Industrial Science and Technology, \\ 1-8-31 Midorigaoka, Ikeda, Osaka 563-8577, Japan \\ ${ }^{2}$ Japan Synchrotron Radiation Research Institute (JASRI/SPring-8), Kouto, Sayo-cho, Hyogo 679-5198, Japan \\ ${ }^{3}$ Kanazawa Institute of Technology, 7-1 Ohgigaoka, Nonoichi, Ishikawa 921-8501, Japan \\ ${ }^{4}$ Nara Institute of Science and Technology, 8916-5 Takayama-cho, Ikoma, Nara 630-0192, Japan
}

(Received November 19, 2018; accepted March 25, 2019)

Keywords: glass, copper, XAFS, photoluminescence, scintillation

$\mathrm{Cu}$-doped aluminophosphate glasses, whose chemical compositions have been used as the host for Ag-doped radiophotoluminescence (RPL) glass detectors, were prepared in order to examine the relationship between the valence state of $\mathrm{Cu}$ and the luminescence properties. Although most of the $\mathrm{Cu}$ cations in these glasses were in the divalent state, which was confirmed by optical absorption and X-ray absorption fine structure (XAFS) measurements, emission from $\mathrm{Cu}^{+}$was observed in addition to the emission from the host matrix. It is expected that the reason for the low conversion efficiency will be the low stability of $\mathrm{Cu}^{+}$ species compared with $\mathrm{Ag}^{+}$in the same phosphate glasses.

\section{Introduction}

After ionized radiation, some materials exhibit luminescence under UV light, and the intensity changes linearly with the irradiation dose. The radiation-induced luminescence, which can be observed by UV irradiation, is called radiophotoluminescence (RPL). ${ }^{(1-4)}$ Among the well-known RPL materials are silver-doped phosphate glasses, which were first reported in the $1950 \mathrm{~s} .{ }^{(1)}$ In the reported RPL mechanism in silver-doped phosphate glasses, $\mathrm{Ag}^{+}$cations in the glass are changed into $\mathrm{Ag}^{0}$ and $\mathrm{Ag}^{2+}$ by radiation. Since the concentrations of photoactive silver species are proportional to the irradiation dose, the Ag-doped glasses have been used as RPL glass detectors. One of the RPL glasses is the so-called FD-7 glass developed by Yokota and coworkers. ${ }^{(5-7)}$ Although the glass system was first reported more than 50 years ago, its chemical composition is still widely in use. ${ }^{(8)}$

Considering the periodic table, one may expect that copper can play a similar role to silver in RPL. It is indeed reported that copper-doped aluminoborosilicate glasses also exhibit RPL behavior. ${ }^{(9)}$ However, copper-doped glasses are not yet commercially available. In order to clarify the reason for this, we focus on the valence state of cations in copper-doped glasses.

*Corresponding author: e-mail: hirokazu.masai@aist.go.jp

https://doi.org/10.18494/SAM.2019. 2190 
There are several techniques for evaluating the valence states of cations. Among these techniques, the X-ray absorption fine structure (XAFS) is one of the strongest tools, because it provides structural information for trace amounts of various elements. ${ }^{(10-13)}$

In the present study, we measured the $\mathrm{Cu}$ K-edge X-ray absorption near-edge structure (XANES) of $\mathrm{Cu}$-doped phosphate glasses to clarify the valence states. As host glasses, we selected three glasses whose compositions were previously reported. ${ }^{(5)}$ Based on the valence estimation, we examined the relationship between the valence state of $\mathrm{Cu}$ and the photoluminescence (PL) and $\mathrm{X}$-ray-induced scintillation properties of these $\mathrm{Cu}$-doped phosphate glasses, and discussed the difference between $\mathrm{Ag}$ and $\mathrm{Cu}$ in terms of their role in RPL.

\section{Experimental Procedure}

The target glasses were prepared by a conventional melt quenching method. The starting materials were $\mathrm{Al}_{2} \mathrm{O}_{3}, \mathrm{Li}_{2} \mathrm{CO}_{3}, \mathrm{NH}_{4} \mathrm{H}_{2} \mathrm{PO}_{4}, \mathrm{Na}_{2} \mathrm{CO}_{3}$, and $\mathrm{Cu}_{2} \mathrm{O}$. These chemicals were mixed and put into a Pt crucible, and then, the crucible was set in an electric furnace in air. The melting temperature and duration were $1150{ }^{\circ} \mathrm{C}$ and $30 \mathrm{~min}$, respectively. After melting, the melt was poured onto a stainless steel plate to quench it. The glass was annealed at the glass transition temperature $T_{g}$ for $1 \mathrm{~h}$. The chemical compositions of these glasses are listed in Table 1 . Since this work is a reference study of Ag-doped phosphate glasses, the concentration of $\mathrm{Cu}$ was determined according to the molar ratio in the Ag-doped phosphate glasses reported by Yokota. ${ }^{(5)}$ In the study, the valence state of $\mathrm{Cu}$ was not clearly obtained. Thus, metal-based $\mathrm{Cu}$ concentrations are shown in the table.

The $T_{g}$ values of these glasses were measured by differential thermal analysis. The $\mathrm{Cu}$ K-edge XAFS spectra were measured at the BL14B2 beamline of SPring-8 (Hyogo, Japan). The storage ring energy system was operated at $8 \mathrm{GeV}$ with a typical current of $100 \mathrm{~mA}$. The measurements were performed using a $\mathrm{Si}$ (111) double-crystal monochromator in the transmittance or fluorescence mode using a 19-SSD detector at room temperature (RT). Pellet samples for the transmittance measurements were prepared by mixing the granular sample with boron nitride. XAFS data for $\mathrm{Cu}$ foil, $\mathrm{Cu}_{2} \mathrm{O}$, and $\mathrm{CuO}$ were collected using the same conditions for reference. The corresponding analyses were performed by using Athena software. ${ }^{(14)}$ The PL and PL excitation (PLE) spectra were recorded at RT using an F7000 fluorescence spectrophotometer (Hitachi High-Tech., Japan). The optical absorption spectra at RT were recorded using a U4150 UV-vis-NIR spectrometer (Hitachi High-Tech., Japan). The absolute quantum yields (QYs) of the glasses were measured using a Quantaurus-QY integrating sphere (Hamamatsu Photonics, Japan). The error bars were \pm 2 . The emission decay at RT was

Table 1

Chemical compositions of $\mathrm{Cu}$-doped phosphate glasses.

\begin{tabular}{lccrcr}
\hline \multirow{2}{*}{ Name } & \multicolumn{5}{c}{ Chemical composition (mol\%) } \\
\cline { 2 - 6 } & $\mathrm{Cu}$ & $\mathrm{Al}_{2} \mathrm{O}_{3}$ & $\mathrm{Li}_{2} \mathrm{O}$ & $\mathrm{P}_{2} \mathrm{O}_{5}$ & $\mathrm{Na}_{2} \mathrm{O}$ \\
\hline ID1 & 3.1 & 10.0 & 27.5 & 59.4 & 0.0 \\
ID2 & 0.6 & 13.3 & 0.0 & 63.2 & 22.9 \\
ID3 & 0.2 & 13.2 & 0.0 & 58.9 & 27.7 \\
\hline
\end{tabular}


measured using a Quantaurus-Tau system (Hamamatsu Photonics, Japan) using white light with a band-pass filter. These PL measurements were done by using samples without X-ray irradiation, because the optical and emission properties might have changed after irradiation. The X-ray-induced scintillation spectra at RT were measured using a monochromator equipped with a CCD detector (Andor DUS420-BU2). ${ }^{(15,16)}$ The irradiation dose was calibrated by using an ionization chamber.

\section{Results and Discussion}

The $T_{g}$ values of the ID1, ID2, and ID3 glasses were 425,480 , and $455{ }^{\circ} \mathrm{C}$, respectively. Figure 1 shows optical absorption spectra of these $\mathrm{Cu}$-doped phosphate glasses. The absorption bands at $1.4 \mathrm{eV}$ are characteristic absorptions of $\mathrm{Cu}^{2+} \cdot{ }^{217-20)}$ The absorption coefficients of these peaks are roughly proportional to the $\mathrm{Cu}$ concentration.

In order to determine the valence state of copper, $\mathrm{Cu}$ K-edge XAFS measurement was performed. Figure 2(a) shows $\mathrm{Cu}$ K-edge XANES spectra of $\mathrm{Cu}$-doped phosphate glasses along with those of $\mathrm{Cu}$ foil, $\mathrm{Cu}_{2} \mathrm{O}$, and $\mathrm{CuO}$ as references. The absorption edge energy of $\mathrm{Cu}$ increases with increasing valence state of $\mathrm{Cu} .{ }^{(21,22)}$ By comparison with the three references, we can conclude that most of the $\mathrm{Cu}$ species in these glasses take the divalent state. Although the result is consistent with the data of optical absorption shown in Fig. 1, it is different from

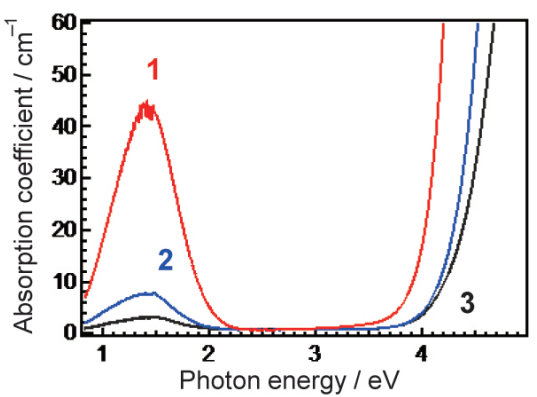

Fig. 1. (Color online) Optical absorption spectra of $\mathrm{Cu}$-doped phosphate glasses.

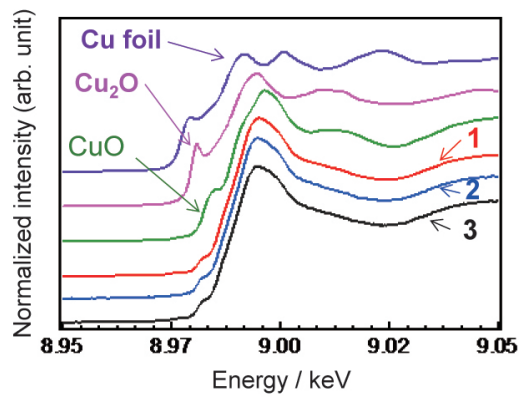

(a)

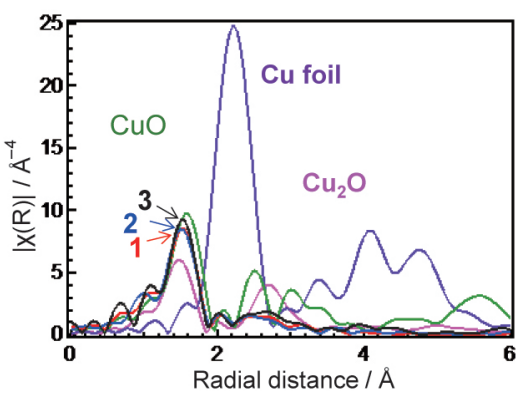

(b)

Fig. 2. (Color online) (a) $\mathrm{Cu}$ K-edge XANES spectra of $\mathrm{Cu}$-doped phosphate glasses along with those of $\mathrm{Cu}$ foil, $\mathrm{Cu}_{2} \mathrm{O}$, and $\mathrm{CuO}$ as references. (b) FT of XAFS spectra of these glasses along with the references. 
the conventional understanding of $\mathrm{Ag}$ in glasses, in which $\mathrm{Ag}$ cations take a monovalent state. Figure 2(b) shows the $|\mathrm{FT}(\mathrm{R})|$ of the XAFS spectra with the $k$ range from 3 to $13 \AA^{-1}$. It is found that the $\mathrm{Cu}-\mathrm{O}$ distances of these glasses are slightly shorter than that of $\mathrm{CuO}$, and no significant difference depending on the composition is observed. After X-ray irradiation, we could not observe the clear formation of color centers in all glasses. It is expected that $\mathrm{Cu}^{+}$species will be less stabilized than $\mathrm{Ag}^{+}$in the same phosphate glasses.

Figure 3 shows PL-PLE contour plots of the $\mathrm{Cu}$-doped glasses along with that of the nondoped glass. The PL intensity of ID1 is smaller than those of the other glasses because of self-absorption. As shown in Fig. 3, two emission bands, $\alpha$ and $\beta$, are observed in the $\mathrm{Cu}$-doped glasses, and only the $\beta$ band is also observed in the nondoped glass, whose host composition is the same as ID3 [see Fig. 3(d)]. Thus, the $\alpha$ band is due to $\mathrm{Cu}$ species, whereas the $\beta$ band is derived from the host glass. ${ }^{(23)}$ In order to understand this easily, PL-PLE spectra of the $\alpha$ and $\beta$ bands are shown in Figs. 4(a) and 4(b), respectively. It is expected that the observed emission will be derived from $\mathrm{Cu}^{+}$species, in which the $\mathrm{d}^{9} \mathrm{~s} \rightarrow \mathrm{d}^{10}$ transition is observed. ${ }^{(24-28)}$ It is reported that this emission is affected by the local coordination field. Since the photon energies of emission bands in Fig. 4(a) are almost the same, it is expected that the local coordination

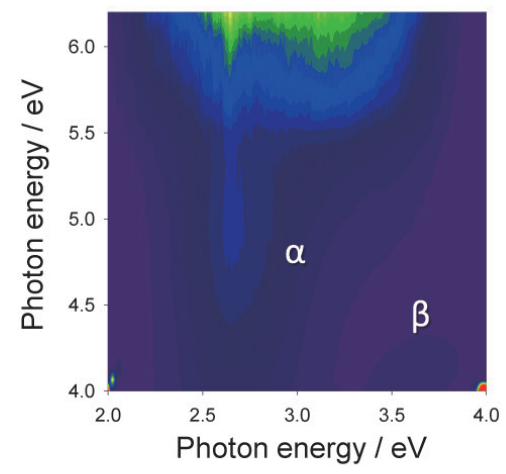

(a)

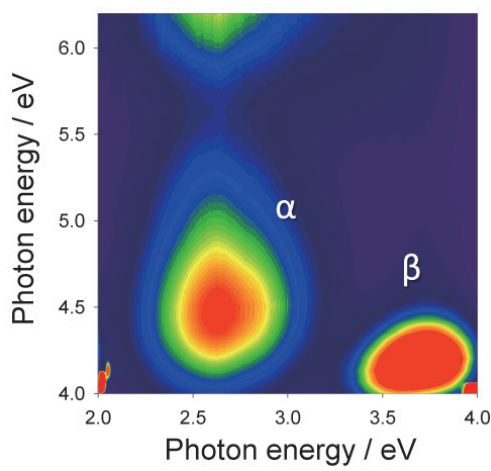

(c)

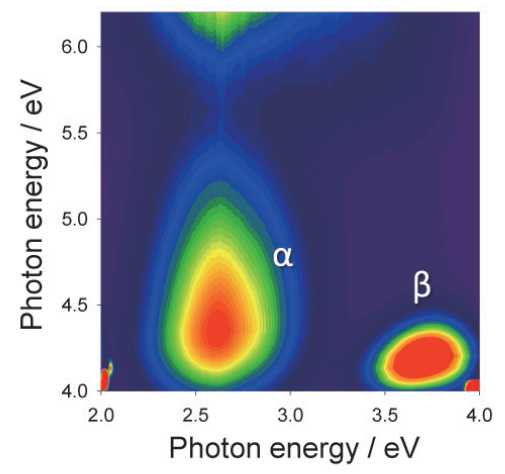

(b)

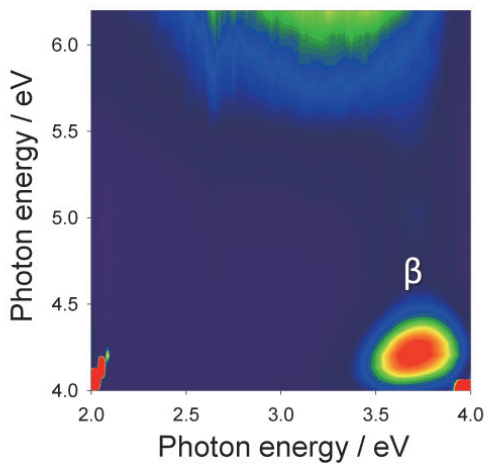

(d)

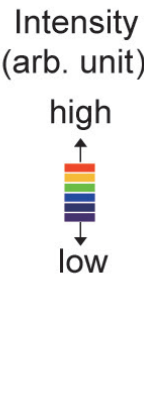

high

Fig. 3. (Color online) PL-PLE contour plots of the $\mathrm{Cu}$-doped phosphate glasses (a) ID1, (b) ID2, (c) ID3, and (d) the nondoped phosphate glass. Vertical and horizontal axes represent the excitation and emission energies, respectively. 


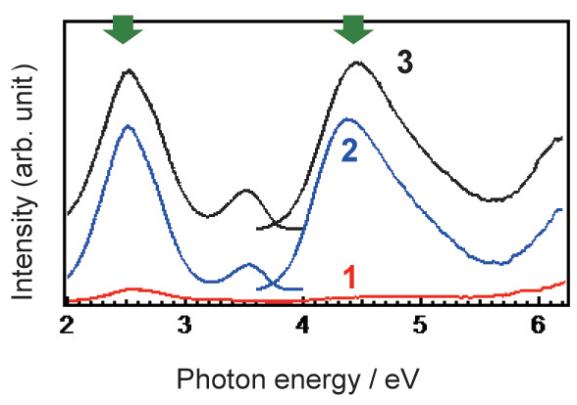

(a)

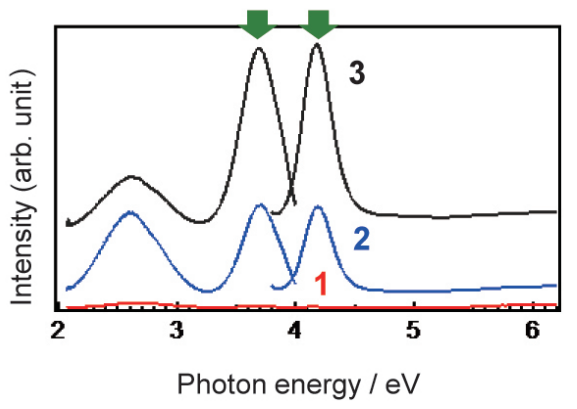

(b)

Fig. 4. (Color online) PL-PLE spectra of Cu-doped phosphate glasses at (a) $\alpha$ and (b) $\beta$ bands. Green arrows indicate excitation and emission energies of each spectrum.

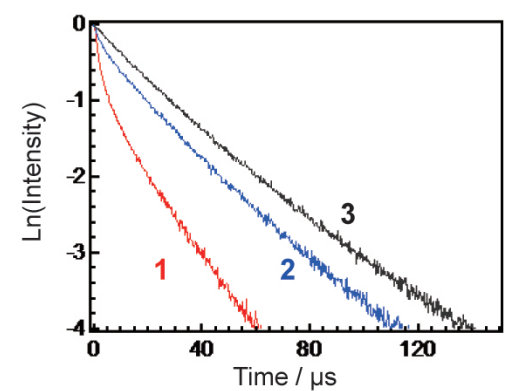

Fig. 5. (Color online) PL decay curves of $\mathrm{Cu}$-doped phosphate glasses.

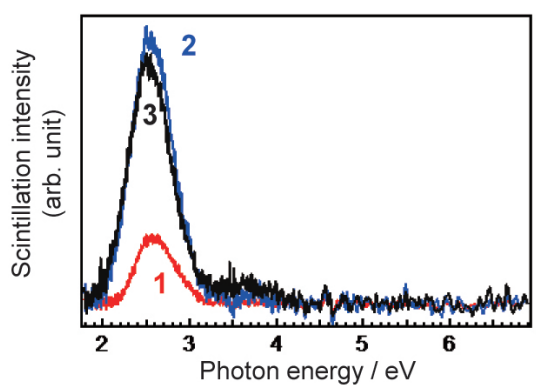

Fig. 6. (Color online) Scintillation spectra of $\mathrm{Cu}-$ doped phosphate glasses.

states of $\mathrm{Cu}^{+}$species in these glasses will be similar. It is notable that a very small amount of $\mathrm{Cu}^{+}$species, which was not detected in XAFS measurement, can act as emission centers. That is why the QYs of these Cu-doped phosphate glasses are less than $4 \%$.

In order to confirm the emission from $\mathrm{Cu}^{+}$centers, we measured PL decay curves of these glasses as shown in Fig. 5. All curves exhibit a nonlinear decay profile, which suggests that (1) emission from the host is partially included, and (2) concentration quenching occurs, especially in ID1. The $\tau_{1 / \mathrm{e}}$ values of the ID1, ID2, and ID3 glasses are 24,30 , and $35 \mu \mathrm{s}$, respectively. Since these $\tau_{1 / \mathrm{e}}$ values are similar to that of $\mathrm{Cu}^{+}$centers, ${ }^{(28)}$ it is suggested that the observed emission mainly originated from the trace amount of $\mathrm{Cu}^{+}$centers in these glasses.

Because the mechanism of PL is different from that of X-ray-induced scintillation, the energy transfer process from the host matrix can be discussed by comparison of these luminescences. Figure 6 shows X-ray-induced scintillation spectra of these Cu-doped phosphate glasses at RT. The peak areas are normalized by the volume of each sample. Since $\mathrm{Cu}$ is the heaviest element in these compositions, it is expected that the intensity will be affected by the $\mathrm{Cu}$ concentration. The ID1 glass exhibits the lowest intensity among these glasses despite having the highest $\mathrm{Cu}$ concentration. On the other hand, the intensity of the ID3 glass is comparable to that of the ID2 glass, although the $\mathrm{Cu}$ concentration of the former is one-third that of the latter. This is mainly due to the concentration quenching suggested by the PL decay curves (Fig. 5). It is notable that 
the scintillation intensity of the host matrix is much lower than that of $\mathrm{Cu}^{+}$centers, although the emission is clearly observed in the PL spectra. Thus, the defects in these host matrixes are not active for X-ray irradiation under these experimental conditions. Since the origin of the defects in the host glass is not clarified, it is suggested that they are phosphate-related species, whose intensity may be changed by X-ray irradiation. ${ }^{(23)}$

\section{Conclusions}

We have prepared $\mathrm{Cu}$-doped aluminophosphate glasses and measured their optical and luminescent properties. The results of $\mathrm{Cu}-\mathrm{K}$ edge XANES spectra suggest that most of the $\mathrm{Cu}$ species are $\mathrm{Cu}^{2+}$ states, although the existence of $\mathrm{Cu}^{+}$species was detected by PL and X-ray scintillation. Considering that Ag cations exist in these host glasses in the monovalent state, we conclude that the stable valence state of each cation in the same glass is different, even though copper and silver are both in group 11.

\section{Acknowledgments}

This work was partially supported by Japan Society for the Promotion of Science Grantin-Aid for Scientific Research (B) Number 18H01714. The synchrotron radiation experiments were performed at BL14B2 of SPring-8 with the approval of the Japan Synchrotron Radiation Research Institute (JASRI) (Proposal No. 2018B1557). The authors also acknowledge the Cooperative Research Project of Research Institute of Electronics, Shizuoka University.

\section{References}

1 J. H. Schulman, R. J. Ginter, and C. C. Klick: J. Appl. Phys. 22 (1951) 1479.

2 J. H. Schulman and H. W. Etzel: Science 118 (1953) 184.

3 R. Yokota and H. Imagawa: J. Phys. Soc. Jpn. 20 (1965) 1537.

4 R. Yokota and H. Imagawa: J. Phys. Soc. Jpn. 23 (1966) 1038.

5 R. Yokota: OYO BUTURI 40 (1971) 1292 (in Japanese).

6 R. Yokota and S. Nakajima: Health Phys. 11 (1965) 241.

7 R. Yokota, Y. Muto, J. Naoi, and I. Yamaji: Health Phys. 20 (1971) 662.

8 Y. Miyamoto, Y. Takei, H. Nanto, T. Kurobori, A. Konnai, T. Yanagida, A. Yoshikawa, Y. Shimotsuma, M. Sakakura, K. Miura, K. Hirao, Y. Nagashima, and T. Yamamoto: Radiat. Meas. 46 (2011) 1480.

9 R. Hashikawa, Y. Fujii, A. Kinomura, T. Saito, A. Okada, T Wakasugi, and K. Kadono: J. Am. Ceram. Soc. 102 (2019) 1642.

10 H. Masai, H. Miyata, Y. Yamada, S. Okumura, T. Yanagida, and Y. Kanemitsu: Sci. Rep. 5 (2015) 11224.

11 H. Masai, T. Yanagida, T. Mizoguchi, T. Ina, T. Miyazaki, N. Kawaguti, and K. Fukuda: Sci. Rep. 5 (2015) 13332.

12 H. Masai, T. Ina, and K. Mibu: Sci. Rep. 8 (2018) 415.

13 H. Masai, G. Okada, A. Torimoto, T. Usui, N. Kawaguchi, and T. Yanagida: Sci. Rep. 8 (2018) 623.

14 B. Reval and M. Newville: J. Synchrotron Radiat. 12 (2005) 537.

15 T. Yanagida, K. Kamada, Y. Fujimoto, H. Yagi, and T. Yanagitani: Opt. Mat. 35 (2013) 2480.

16 T. Yanagida: Proc. Jpn. Acad. B 94 (2018) 75.

17 B.-S. Bae and M. C. Weinberg: J. Non-Cryst. Solids 168 (1994) 223.

18 S. Sakka, K. Kamiya, and H. Yoshikawa: J. Non-Cryst. Solids 27 (1978) 289.

19 H. Hosono, H. Kawazoe, and T. Kanazawa: J. Non-Cryst. Solids 33 (1979) 103.

20 S. Ohara, H. Masai, Y. Takahashi, T. Fujiwara, Y. Kondo, and N. Sugimoto: J. Ceram. Soc. Jpn. 116 (2008) 1083. 
21 I.-H. Tseng, J. C. S. Wu, and H.-Y. Chou: J. Catal. 221 (2004) 432.

22 A. L. Yusoff, R. P. Hugtenburg, and D. A. Bradley: Radiat. Phys. Chem. 74 (2005) 459.

23 D. L. Griscom, E. J. Friebele, K. J. Long, and J. W. Fleming: J. Appl. Phys. 54 (1983) 3743.

24 J. Simonetti and D. S. McClure: Phys. Rev. B 16 (1977) 3887.

25 S. A. Payne, A. B. Goldberg, and D. S. McClure: J. Chem. Phys. 81 (1984) 1529.

26 R. Debnath and S. K. Das: Chem. Phys. Lett. 155 (1989) 52.

27 R. F. Wei, C. G. Ma, Y. L. Wei, J. Y. Gao, and H. Guo: Opt. Express 20 (2012) 29743.

28 A. Jiménez: J. Phys. Chem. Solids 85 (2015) 212. 